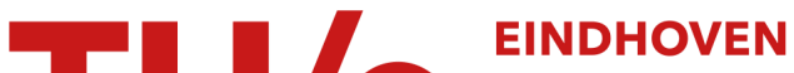 \\ UNIVERSITY OF \\ TECHNOLOGY
}

\section{Leaky-wave slot array antenna fed by a dual reflector system}

Citation for published version (APA):

Ettorre, M., Neto, A., Gerini, G., \& Maci, S. (2008). Leaky-wave slot array antenna fed by a dual reflector system. IEEE Transactions on Antennas and Propagation, 56(10), 3143-3149. https://doi.org/10.1109/TAP.2008.929457

DOI:

10.1109/TAP.2008.929457

Document status and date:

Published: 01/01/2008

\section{Document Version:}

Publisher's PDF, also known as Version of Record (includes final page, issue and volume numbers)

\section{Please check the document version of this publication:}

- A submitted manuscript is the version of the article upon submission and before peer-review. There can be important differences between the submitted version and the official published version of record. People interested in the research are advised to contact the author for the final version of the publication, or visit the $\mathrm{DOI}$ to the publisher's website.

- The final author version and the galley proof are versions of the publication after peer review.

- The final published version features the final layout of the paper including the volume, issue and page numbers.

Link to publication

\section{General rights}

Copyright and moral rights for the publications made accessible in the public portal are retained by the authors and/or other copyright owners and it is a condition of accessing publications that users recognise and abide by the legal requirements associated with these rights.

- Users may download and print one copy of any publication from the public portal for the purpose of private study or research.

- You may not further distribute the material or use it for any profit-making activity or commercial gain

- You may freely distribute the URL identifying the publication in the public portal.

If the publication is distributed under the terms of Article 25fa of the Dutch Copyright Act, indicated by the "Taverne" license above, please follow below link for the End User Agreement:

www.tue.nl/taverne

Take down policy

If you believe that this document breaches copyright please contact us at:

openaccess@tue.nl

providing details and we will investigate your claim. 


\title{
Leaky-Wave Slot Array Antenna Fed by a Pin-Made Planar Dual Offset Gregorian Reflector System
}

\author{
M. Ettorre ${ }^{1}$, A. Neto ${ }^{1}$, G. Gerini ${ }^{1}$, S. Maci ${ }^{2}$ \\ ${ }^{1}$ TNO Defense and Security, Den Haag 2597 AK, The Netherlands. \\ mauro.ettorre, andrea.neto, giampiero.geriniatno.nl. \\ ${ }^{2}$ University of Siena via Roma 56, 53100 Siena, Italy \\ macis@di.unisi.it
}

\begin{abstract}
This work proposes a leaky-wave slot array antenna fed by a dual offset Gregorian reflector system realized by pins in a parallel plate waveguide. The radiating part of the antenna is composed by parallel slots etched on one side of the same parallel plate waveguide. The dual offset Gregorian reflector system is fed by an arrangement constituted by two vias and a grid, also constituted by pins. A prototype of the antenna has been designed, manufactured and successfully tested. The low profile, low cost and high efficiency of the antenna render it suited for a variety of radar or telecom applications.
\end{abstract}

\section{INTRODUCTION}

Planar leaky-wave antennas (LWAs) have received much attention in the recent years [1], [2] for applications in the millimeter-wave ranges. In particular the compatibility with printed circuit board technology (PCB) and the low profile are the strongest features of these antennas. Mono dimensional planar leaky-wave antennas, as in [3], are characterized by a fan beam; then, array solutions or two-dimensional planar leaky-wave antennas are needed to radiate a pencil beam. An array solution of mono dimensional planar leaky-wave antennas would have the disadvantages of a cumbersome feeding network accompanied by a probable low efficiency. On the other hand two-dimensional leaky-wave antennas have the advantage of absence of the feeding network, but they are less flexible for beam shaped designing. The pencil beam leaky-wave antenna presented here, an array of slots etched on one plate of a parallel plate waveguide (PPW) is fed by a dual offset Gregorian reflector system realized by vias connecting the two plates of the PPW. The antenna is shown in Fig. 1. A probe-type source has been used to feed the Gregorian system which effectively implements the Mizugutch's condition [4] so that it is possible to feed the reflector off focus without significantly altering the off focus beam performances. This arrangement is suited to printed circuit board fabrication processes. Furthermore it has the advantage to avoid a beam forming network while preserving the freedom to shape the amplitude of the plane feeding wavefront. The azimuth and elevation plane of the slot array can be thus shaped independently by acting on the focal plane feeding of the Gregorian system and on the parameters of the leaky-wave radiating slots. This leads various degree of freedom in the design.

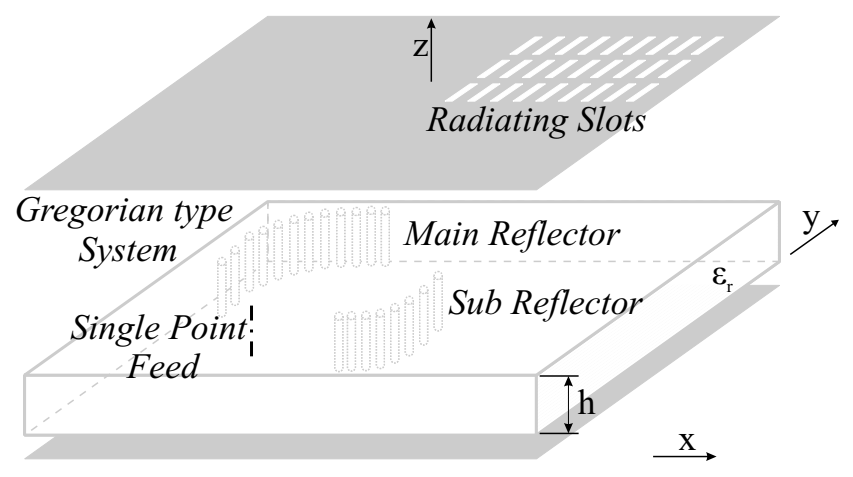

(a)

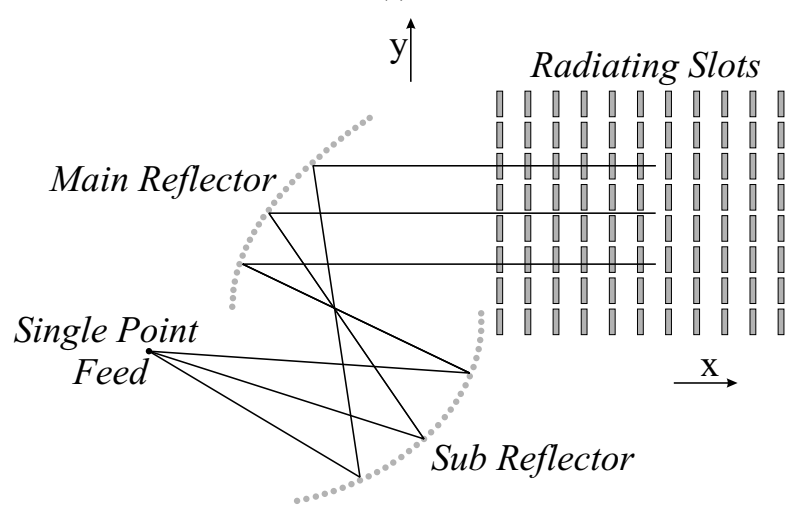

(b)

Fig. 1. (a) 3-D view of the antenna. The dual reflector feed system is made by pins connecting the two plates of the parallel plate waveguide. (b) Top view of the antenna.

In particular a frequency reuse scheme renders possible the scanning in the E-plane, while a multi-feed focal plane renders possible the scanning in the E-plane. Overall this solution opens possibilities for those applications that are right now implemented with 3-D focusing imaging-like systems.

\section{RADIATING SLOTS}

The radiating part of the system is composed by an array of slots etched on the upper plate of a parallel plate waveguide structure, operating in a backward leaky-wave mode. In the working bandwidth $(9.1-9.6 \mathrm{GHz})$, the periodicity of the 


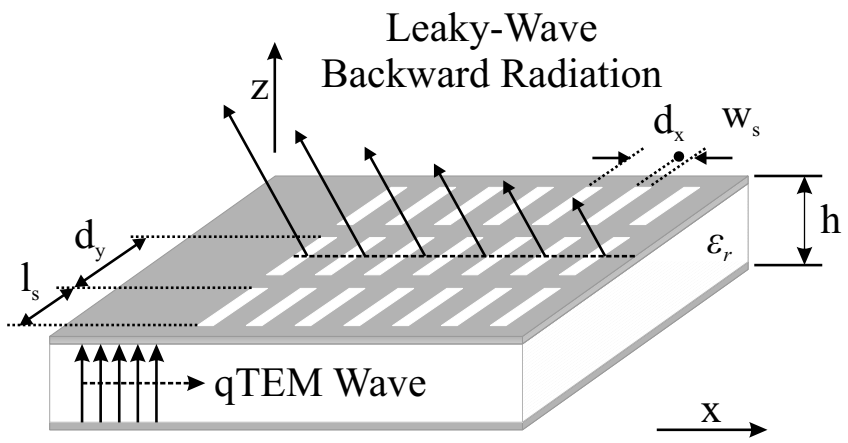

Fig. 2. Geometry of the radiating slots. The slots are etched on the upper plate of the parallel plate waveguide. The periodicity of the slots is such as to have a backward radiation in the operating band.

slots gives reason of a backward radiation in the $x-z$ plane, as in Fig. 2.

While the procedure to derive the dispersion equation characterizing such a structure will not be given here, it is important to highlight the effect of the most significant geometrical parameters that affect the dispersion equation. These considerations will give approximate equations to predict the radiation properties of the slots.

In particular the basic radiation mechanism is the following. In absence of the slots a $q T E M$ plane wave would propagate along the surface with real propagation constant $k_{q T E M}$ essentially equal to $k_{0} \sqrt{\epsilon_{r}}$. When the $q T E M$ wave encounters the slot region, part of the energy reflects back in form of $q T E M$ plane wave and part progresses in the slotted waveguide region in form of leaky-wave. The dominant -1 indexed $L W$ of the Floquet mode expansion for periodic structures is given by:

$$
k_{x_{-1}}=k_{x_{0}}-\frac{2 \pi}{d_{x}}
$$

It follows that the leaky wave beam angle can be approximated as:

$$
\theta \approx \arcsin \left(\frac{k_{x_{0}}(\omega)-\frac{2 \pi}{d_{x}}}{k_{0}}\right)
$$

It is apparent from (2) that the beam pointing angle exhibits a variation vs. frequency which is caused by the non linearity of $k_{x_{-1}}$ with frequency, also within the first approximation that assumes that the zero mode runs with the phase velocity of the incident wave, (i.e. $k_{x_{0}}=k_{q T E M}$ ). The differences between the real radiation angle measured or calculated with full wave techniques, [3], and the angle according to the present simplification is in the order of $20^{\circ}$ and thus one can use the simplified formula as starting design point.

\section{PROTOTYPE AND EXPERIMENTAL RESULTS}

An antenna prototype has been built and measured. Moreover the number of radiating slot rows have been chosen to reduce the surface wave field at the last row of slots to less than $1 / 10$, indicating that $99 \%$ leaky-wave end point efficiency is achieved. The number of slot rows is 23 . The antenna dimensions are $378 \times 596 \mathrm{~mm}$ while the panel size

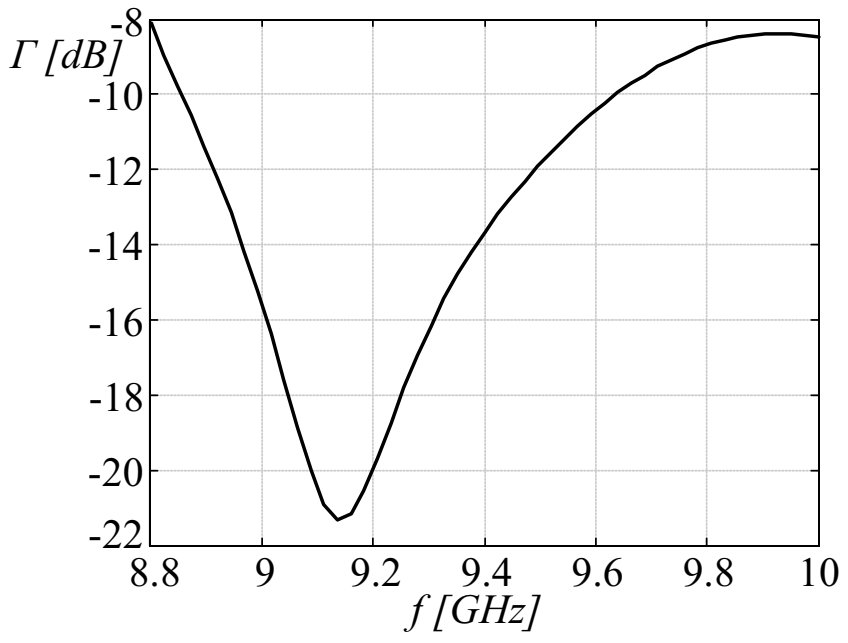

Fig. 3. Measured Input Reflection Coefficient.

where the antenna is built is $457 \times 610 \mathrm{~mm}$. For the dielectric a laminate Rogers RT Duroid 5880 has been used. The reflection coefficient and the radiation patterns of the antenna have been measured. The measured input reflection coefficient is shown in Fig. 3.

The normalized measured radiation patterns on the E-plane are reported in Fig. 4. Fig. 5 shows the measured radiation

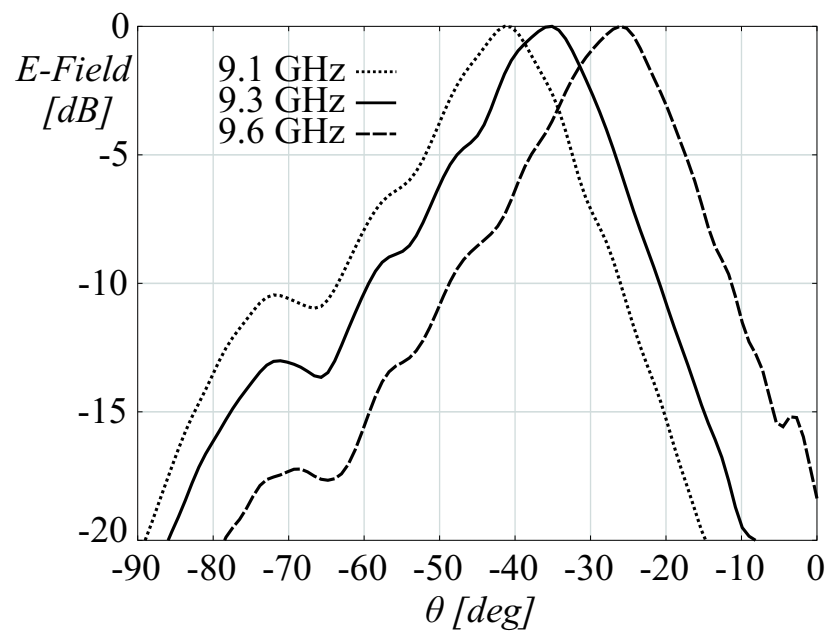

Fig. 4. Measured radiation patterns in the E-plane at different frequencies $\theta$ is the usual elevation angle starting from the normal to the plane of the antenna.

patterns on the E-plane and H-plane at the frequency $f=$ $9.3 \mathrm{GHz}$. On the E-plane we observed a $3-d B$ beamwidth of $B W \approx 12.6^{\circ}$ and on the $\mathrm{H}$-plane of $B W \approx 9.9^{\circ}$. The patterns on these two planes could be shaped independently within a certain degree of freedom. In fact the patten on the E-plane is dictated by the leaky wave contribution. In particular the $3-d B$ beamwidth is proportional to the attenuation constant of the leaky wave and the pointing angle is related to the propagation constant of the leaky wave. The pattern on the $\mathrm{H}$-plane is linked to the dual reflector system and then to its 


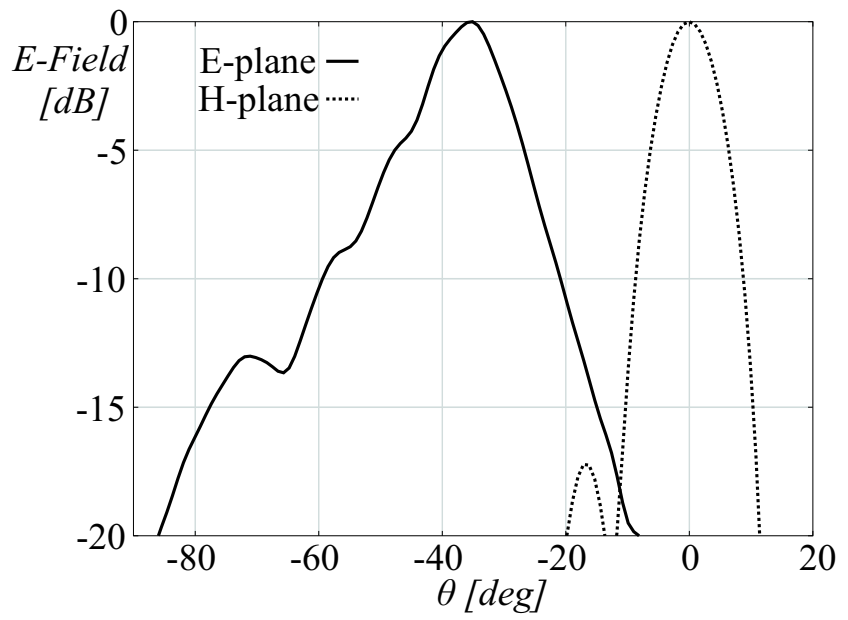

Fig. 5. Measured Radiation Patterns: electric field at the frequency $(9.3 \mathrm{GHz})$ on the E-plane and H-plane. $\theta$ is the usual elevation angle starting from broadside for the E-plane and from the direction of maximum radiation for the H-plane.

physical dimensions and type of feeding.

Finally cross-polarization levels, always lower than $-40 \mathrm{~dB}$ from cross to co-component maximum, are not reported for the sake of brevity.

\section{CONCLUSiON}

A dual offset Gregorian system leaky-wave antenna realized in PCB technology has been presented. An antenna prototype has been manufactured and tested. The measured radiation patterns as a function of the frequency have been presented. A pin-made feed, that uses EBG concepts, PCB extension of the one presented in [5], has been used to efficiently feed the dual reflector system. However it has not been discussed here for the sake of brevity. Good performance of the antenna has been observed. The planar dual reflector system could be used in future planar imaging system applications to achieve antennas with independent beams in the azimuth and elevation planes, resorting to frequency reuse and multiple focal plane feeds. The scanning of the pointing angle with the frequency is observed. In particular since the final user of these antenna is a radar system whose beam is scanned as a function of the frequency, the frequency squint that was observed in Fig. 4 should not be considered a disadvantage.

\section{REFERENCES}

[1] T. Zhao, D. R. Jackson, J. T. Williams, H. D. Yang, A.A Oliner, "2D Periodic Leaky-Wave Antennas- Part I: Metal Patch Design”, IEEE Transactions on Antennas and Propagation, Vol. 53, no.11, pp. 35053514, Nov. 2005.

[2] T. Zhao, D. R. Jackson, J. T. Williams, "2-D Periodic Leaky-Wave Antennas- Part II: Slot Design”, IEEE Transactions on Antennas and Propagation, Vol. 53, no.11, pp. 3515-3524, Nov. 2005.

[3] M. Ettorre, S. Bruni, N. Llombart, A. Neto, G. Gerini, S. Maci, "Sector PCS-EBG Antenna for Low-Cost High-Directivity Applications", IEEE Antennas Wireless Propag. Lett., Vol. 6, pp. 537-539, 2007.

[4] Y. Mizuguchi, M. Akagawa, H. Yokoi, "Offset Gregorian antenna”, Trans Inst. Electron. Commun. Eng. Japan, Vol. 161-B, no.3, pp. 166-173, Mar. 1978.
[5] A. Neto, N. Llombart, G. Gerini, M. D. Bonnedal, P. De Maagt, "EBG Enhanced Feeds for the Improvement of the Aperture Efficiency of Reflector Antennas", IEEE Transactions on Antennas and Propagation, Vol. 55, no.8, pp. 2185-2193, Aug. 2007. 